\title{
Long-term ecological research in Australia: innovative approaches for future benefits
}

\author{
Jean-Marc Hero', J. Guy Castley', Mikalah Malone', Ben Lawson',and \\ William E. Magnusson ${ }^{2}$
}

\author{
' Environmental Futures Centre, Griffith School of Environment, Gold Coast campus \\ Griffith University, QId 4222, Australia. e-mail: m.hero@griffith.edu.au
}

${ }^{2}$ Instituto Nacional de Pesquisas da Amazonia (INPA), CP 478, 690 I I-970 Manaus AM, Brazil.

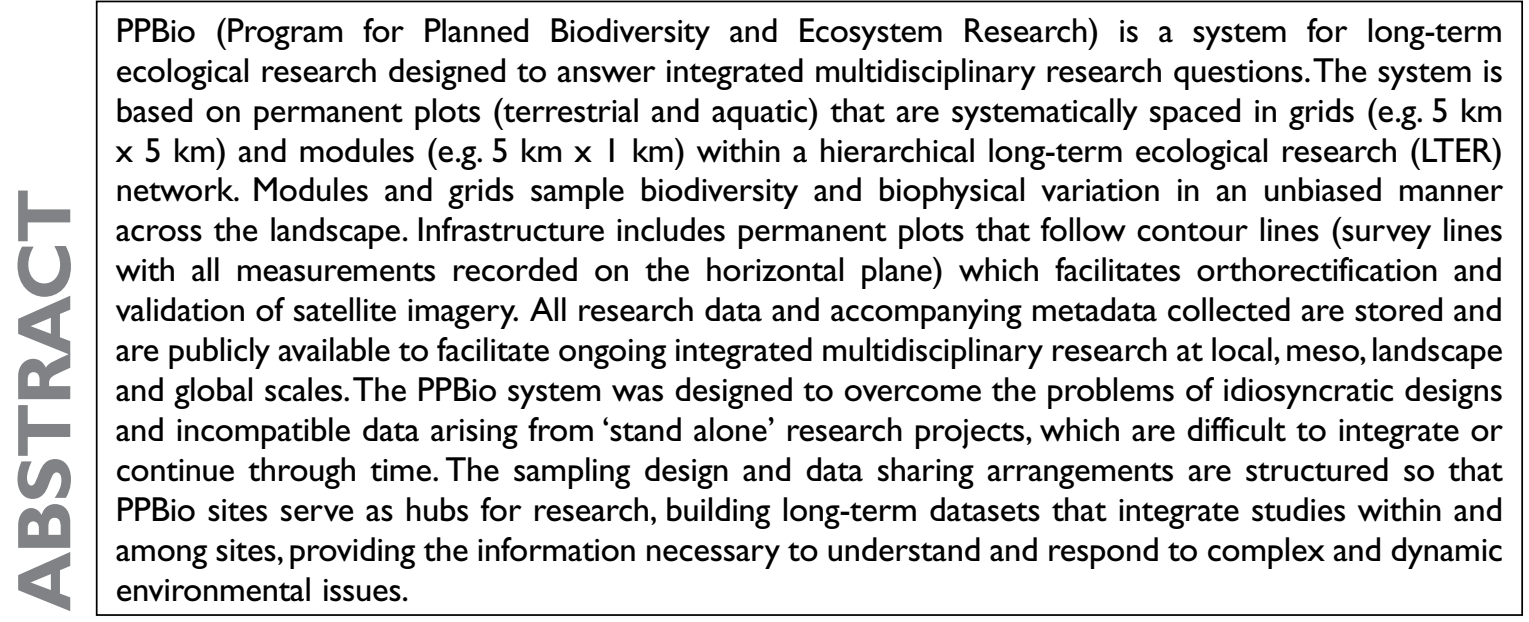

Key words: Biodiversity Monitoring, Condition Assessment, LTER, ILTER, data management, natural resource management, long-term ecological research

\section{Biodiversity monitoring and the need for long-term ecological research}

Land managers in Australia and across the globe face many challenges in responding to complex and dynamic ecological phenomena. Effective management of natural resources is dependent on robust scientific information, with long-term data being particularly valuable in understanding how ecosystems respond to events such as climate change or management interventions (Hughes 2000; Stork et al 1996).

Nations across the globe grapple with the challenge of meeting the 2010 Convention on Biological Diversity targets for conservation and sustainable use, but attainment of these goals is underpinned by assessments of baseline conditions (inventories) and trends in these conditions (monitoring) (Stork et al 1996). There is little doubt that biological research and monitoring is an important scientific activity that will enable scientists and managers to review the impacts of both natural and anthropogenic impacts on our natural environments facilitating a reporting on the state of the environment (e.g. Beeton et al 2006). However, the manner in which such monitoring should be undertaken remains a vigorous point of discussion (Purvis and Hector 2000; Yoccoz et al 2001; Nielsen et al 2007).

In response to the need for nationwide measures of biodiversity a number of countries have developed 1 arge scale monitoring initiatives (see reviews by Wiser et al 2001; Craine et al 2007) with some building on historical data archives (e.g. Wiser et al 2001) and others developing strategies that encompass entire countries (e.g. Lane 1997, Swiss Biodiversity Monitoring Programme; Hintermann et al 2002). Perhaps the most well known of these approaches is the LTER program, initiated by the National Science Foundation in the USA in the late 1970's (Callahan 1984, Hobbie et al 2003), aimed at addressing the need for long-term studies addressing large scale issues. Global interest in the need for long-term research prompted the establishment of an international network of sites for long-term ecological research (ILTER). At present 37 counties have established LTER networks as part of this global initiative and Australia is included as one of these participating nations (see http://www.ilternet. edu). However, the manner in which these ILTER networks are managed and the level of coordination among the sites is highly variable. For example the Environmental Change Network (ECN) in the United Kingdom has established a series of 12 terrestrial and 45 freshwater sites. At each of these sites a series of standardised data is collected to build up a national database for environmental monitoring and reporting. Conversely, Australia has only 5 sites listed in a small informal network (see http://www.daff.gov.au/brs/ 
forest-veg/research-sites) which presents considerable deficiencies in providing information critical for efficient environmental reporting across Australia. This shortcoming within the Australian network requires urgent attention and we suggest that the approach outlined in this paper presents a potential solution to this. The need for a more strategic view of long-term ecological research and monitoring is not restricted to Australia and we include examples from Brazil to demonstrate how these long-term objectives can be met.

We believe that there are three key strategies to increasing the efficacy of long-term research and monitoring programs. Firstly, we need to establish improved linkages between science and management in a systems approach that enhances sustainable resource management (Bosch et al 2003). Secondly, research and monitoring needs to occur over long temporal scales to enable the detection of trends in condition which are independent of any human interventions. Thirdly, a combination of structural and functional ecosystem components must be monitored to discern environmental trends. For example, the Environmental Change Network in the United Kingdom has used indicator groups (e.g. butterflies, moths and beetles) to monitor changes in biodiversity in response to climate change (DEFRA 2003). Such long-term ecological data are necessary for natural resource management actions, such as condition assessment, impact assessment, population estimation, planning and modelling, and are dependent on the rapid dissemination of the monitoring information to a multitude of stakeholders.

Long-term ecological data collection and use provides the foundation of ecological research and understanding, yet it remains an area characterised by minimal resources, ad hoc planning and is captive to short-term thinking. Despite the imperative for longterm ecological data, shortcomings in this information are increasingly being highlighted within Australia (e.g. NLWRA 2002; Productivity Commission 2004) and globally (e.g. Pereira and Cooper 2006). The National Land and Water Resources Audit's (NLWRA) Australian biodiversity assessment concluded that "a strategic and systematic approach to monitoring and reporting on Australia's terrestrial biodiversity requires a strategic analysis of the existing database in order to define and clarify information needs and link to other datasets" (p.186) to balance demands on natural resources. However, despite a number of subsequent reviews commissioned by the NLWRA (2004a; 2004b) these analyses are mostly focussed on continuous map coverage and remotely sensed imagery of a region to map vegetation patterns, rather than site-based data which provide direct measures of change. These site specific measures of change are critical to developing an understanding of the trends in condition as remote methods are frequently incompatible (Pereira and Cooper 2006) and are also prone to classification and interpretation errors (Thackway et al 2007).

\section{Complimentary long-term ecological research: speaking from the same ecological page}

The use of long-term ecological research sites to monitor changes in biological condition at local, regional and global scales is appropriately argued (Hobbie et al 2003; Parr et al 2003) but considerable debate remains as to the appropriate measures of such biodiversity within such networks. This symptomatic need for appropriate indicators from long-term ecological research sites is demonstrated by the variation in vegetation condition assessment metrics within Australia. A number of Australian States have developed condition assessment approaches to evaluate broadscale trends in biodiversity condition. The first, and most well known, of these is the Victorian 'Habitat Hectares' approach which is founded upon comparisons between existing vegetation and benchmark sites of the same ecological community in a mature and undisturbed state. A suite of ten habitat attributes are used to prioritise conservation interventions (Parkes et al 2003; McCarthy et al 2004). Similar approaches are being developed and applied in other States, such as 'BioCondition' in Queensland (Eyre et al 2006) and 'BioMetric' in New South Wales (Gibbons et al 2005). Criticism is increasingly being directed at these approaches with regard to perceived errors, inconsistencies and lack of detail. Resolution of such problems is hampered by inadequate spatial and temporal data. A well planned network of long-term research sites across the landscape would be an invaluable asset to assessing, comparing and refining the multitude of condition assessment approaches at such sites over time. Biodiversity condition, and the ecological data that underpins it, are also assuming increased importance within the Australian Government (e.g. DEH 2005). Understanding and tracking these changes in ecological condition and understanding the key influences will be very important, particularly in establishing ecosystem thresholds, deciding when management interventions are justified, monitoring changes resulting from management activities, and the legal enforcement of such actions.

Long-term ecological research sites are necessary to understand and manage ecosystems and Westoby (1991) has urged greater cooperation and research funding incentives to establish and maintain such sites across Australia. Numerous Australian organisations have (or have had) such sites used for many purposes such as fire management, forestry monitoring (e.g. EPA 1999), grazing (e.g. Sinclair 2005) and biodiversity monitoring (e.g. Neldner et al 2004), which could potentially be exploited for broader ecological research. However, the question-specific design, poor awareness, and the limitations of data and sampling methodologies, often limit the wider use of such datasets. For example, such site-based sampling can often have inadequate replication to statistically examine patterns or trends across the landscape (Lawson et al 2007). As a result these isolated sites are poorly comparable and do not therefore contribute to our understanding of ecological processes. Gioia's (2005) assessment of information management in State and Commonwealth conservation agencies 
concluded that these "sites of significance" were of "high strategic significance" (p.27) to biodiversity information systems. He recommended clear identification of these sites and a description of their purposes and attributes (e.g. managed research plot, long-term monitoring) within database systems as vital to their effectiveness. Such a database would be a highly useful starting point for a fundamental reconsideration and restructure of how we collect and use ecological data. In addition, a parallel process of metadata enhancement is needed to enable an assessment of data compatibility and complementarity.

Given the variation in such sites between agencies and States, and the imperative for cost effective use of survey resources (Burbidge 1991; Gardner et al 2008), there exists a need for an audit of these sites to understand their characteristics and to maximise their utility for ecological understanding. Such audits have been undertaken in other countries to provide the basis of long-term ecological research (Chapman and Busby 1994). Analysis from the Eden region of southern NSW showed some analyses were not sensitive to variations in sample size between 0.04 and 0.1 hectare (Keith and Bedward 1998), suggesting that there is some scope for useful comparison and analysis of sites with varied collection methods, albeit with appropriate checking of data comparability. Any review should include sites established for a variety of purposes to determine the suitability of their information.

Across the globe many long-term monitoring programs have been initiated (Wiser et al 2001; Craine et al 2007) although not all of these are affiliated to the ILTER network. Many of these are in regions recognised for their high biodiversity but much of this is relatively poorly understood (e.g. Amazonia in Brazil, Magnusson et al 2008). Many studies have focused on a limited range of taxa, or only abiotic processes, and have widely differing sampling methods which limit their comparability. In some cases, the logistics entailed in regularly resurveying the sites inhibits their wider application (e.g. Tropical Forest Census Plots, Condit 1995, 1998, Magnusson et al 2008).

These challenges have prompted a review of the approaches to long-term ecological research and monitoring (Strayer et al 1986, Ferraz et al 2008) facilitating the development of new approaches such as the Program for Planned Biodiversity Ecosystem Research in Brazil (see reviews by Magnusson et al 2005, 2008). Faced with the challenges of ensuring that long-term ecological research should contribute to biodiversity conservation in a coordinated manner, we will outline options for how such long-term ecological research could be achieved in Australia.

\section{Advancing long-term ecological research and monitoring within Australia}

Site-based ecological data has many possible applications, the scope of which is dependent upon the quality and range of information recorded (Neldner et al 2004). However, these site based approaches have a number of shortcomings and Ferrier (1997) summarised data gaps into three categories, and provides the reasons for them:
- geographical gaps: only a portion of a region can realistically ever be sampled.

- temporal gaps: one-off and short duration surveys don't adequately describe temporal change.

- taxonomic gaps - not all biodiversity elements are sampled each time.

Burbidge (1991) has concluded that the paucity of basic information on the distribution of most taxa across Australia necessitates well-designed surveys serving multiple objectives to achieve scientifically sound nature conservation surveys in a cost-effective manner. The need for these baseline assessments is reiterated not only by the scientific community but also by managers. Worboys (2007a) assessed the responses by protected area and natural resource managers and found that there was an overwhelming need for assessing management performance in response to established baselines. These contextual baseline conditions (fauna, flora, habitats, ecosystems etc.) are critical for benchmarking and inclusion in the adaptive management process (Worboys 2007a). How then can this be implemented within Australia?

We believe that the implementation of a national biodiversity research and monitoring strategy for Australia is both achievable and imperative given the emerging national environmental challenges. There are however, a number of key steps to ensuring that such a system is able to deliver on its objectives. Firstly, the network design has to be flexible to enable support of a multi-scalar approach. Using a multi-scalar approach caters for the scalar variability of environmental structure and function across the landscape and ensures the network can monitor biodiversity at local (site), regional (landscape) and national (biome) scales in a nested hierarchy. Secondly, the selection of monitoring indicators needs to be centred on a core set of variables that provide the basic baseline data which can be supplemented as necessary with site-specific requirements to cover emerging research priorities. The selection of indicator taxa that enable cost-effective monitoring has been strongly argued and vascular plants, birds and dung beetles are frequently identified as being of high value (Pereira and Cooper 2006; Gardner et al 2008) but Lindenmayer et al (2001) urge a cautionary approach and suggest that structure-based indicators may be more appropriate than taxon based indicators in areas where our taxonomic knowledge is limited. Thirdly, the survey methodologies should allow for comparable assessment of biodiversity indicators across a range of spatio-temporal scales. This is critical to enable the accurate detection of trends in condition while also being able to differentiate between trends in response to anthropogenic versus natural drivers. Lastly, data generated from such monitoring need to be housed in a central widely accessible location where both scientists and land managers can access these data in a short time frame to facilitate adaptive management practices that build from the learning experiences arising from the long-term monitoring. 
One approach that is able to meet the requirements of an efficient long-term ecological research and monitoring strategy across Australia, is the RAPELD approach to standardised surveys (rapid assessment surveys at longterm ecological research sites) used by the Program for Planned Biodiversity and Ecosystem Research (PPBio) developed in Brazil (see Magnusson et al 2005). Similar to Australia, Brazil is geographically a large country, has high biotic diversity and heterogeneity, and limited resources for monitoring. RAPELD is a universal meso-scale (> 100ha spatial extent or $>1: 25,000$ spatial resolution, as per Ferrari \& Ferrarini 2008), multidisciplinary system designed for cost-effective and efficient ecological research and data collection. It provides a new model for biodiversity research, monitoring and assessment that can be replicated throughout Australasia, providing an innovative foundation for enhancing environmental management and monitoring the impacts of climate change in the future. The approach is designed to overcome present restrictions facing site-based ecological data collection which are characterised by ad hoc implementation and analysis, single purpose aims, duplication and wasted resources, which ultimately result in non-comparable data of limited ecological value. As such, the PPBio program is one of the few means of achieving these universally relevant aims in a cost-effective framework for ecological research and management, with the potential to also monitor social, political and economic issues and their interactions with environmental systems. Although some existing systems are adequate for some taxa, or particular questions, most are inadequate for the needs of most users (conservation planning, environmental impact assessment, bioprospecting, monitoring of harvesting, environmental reporting etc.). We suggest that the establishment of a network of long-term ecological research sites along ecological gradients in Australia using the PPBio approach would improve the ability of scientists and managers to report on and respond to environmental changes, most notably the effects of climate change.

PPBio aims to assist agencies and land managers in collecting long-term data on biodiversity and ecosystem assessment on public and private lands. The program includes a number of important components:

1. The system is based on permanent plots (terrestrial, aquatic or marine) that are systematically spaced in grids (e.g. $5 \mathrm{~km} \times 5 \mathrm{~km}$ ) and modules (e.g. $5 \mathrm{~km} \mathrm{x} 1 \mathrm{~km}$ ) within a hierarchical long-term ecological research (LTER) network (Magnusson et al 2005, Mendonca et al 2005). This meso-scale approach facilitates the compilation of replicated sampling of local biodiversity and biophysical data but importantly enables the integration of these replicate plots to improve our understanding of biodiversity patterns across broader scales.

2. The RAPELD system is modular in its design and although core grids within the network should adhere to the $5 \mathrm{~km}$ x $5 \mathrm{~km}$ design, smaller site-specific modules (e.g. 5 $\mathrm{km} \times 1 \mathrm{~km}$ ) of both trails and plots can be used to capture specific biodiversity features, experimental treatments, or to sample large areas cost effectively (Magnusson et al 2005).
3. All data collected in the plots will be publicly available on a dedicated internet site (owned by consortium members) together with the associated metadata so that they are available to land managers and other scientists. Data collectors have a two year window to publish results before their data are released. This ensures that these data are rapidly available to inform adaptive management responses, while accommodating the publication needs of researchers.

The strength of the PPBio approach is that it facilitates long-term ecological monitoring of key biotic and abiotic variables, while serving as a hub for dynamic and diverse ecological research responding to emerging priorities (Magnusson et al 2008). The international network of long-term ecological research sites focus multi-disciplinary research on biodiversity and ecosystem processes that allow managers to monitor both the local impacts associated with local management practices, and the long-term changes associated with global climate change.

The implementation of the PPBio approach is underpinned by a robust sampling design that can be replicated in any number of ecosystems at a global scale. This makes the PPBio approach well suited to the Australian situation. The RAPELD design has seven basic standards for such ecological surveys, as outlined by the Brazilian Ministry of Science and Technology (2006):

1. The use of standardised survey methods.

2. The use of integrated multidisciplinary surveys of all taxa.

3. The use of an area of a sufficiently large size to monitor all taxa and ecosystem processes (terrestrial, aquatic and marine).

4. The use of a modular design, to allow comparisons with samples taken over larger areas.

5. The compatibility with existing programs.

6. The ability to be implemented using existing resources.

7. The timely availability of useable data to managers and other stakeholders.

These standards underpin the success of the PPBio model.

\section{Adopting the PPBio model within Australia}

Australian biodiversity conservation and management currently lacks any consolidated approach to monitoring and reporting the condition and trend in condition of environmental variables. This is clearly indicated by the most recent Australian State of the Environment (SoE) report finding that $63 \%$ of SoE reporting indicators had no or inadequate data to base assessments upon (Beeton et al 2006). Existing SoE reporting is focused on a broad scale assessment of a number of indicators to report on trends over five year intervals (Saunders et al 1998; ANZECC 2000) and demands rigorous scientific monitoring to support these broad assessments. An inability to provide accurate reports on biodiversity condition is fuelled by the paucity of comparable long-term studies (Westoby 1991; Hahs 2001; Hughes 2003) demonstrated by Lunt (2002) who outlines the shortcomings of long-term vegetation 
change monitoring across Australia. Few long-term experimental studies exist and long-term changes are derived from comparisons of independent short-term studies prompting the need for initiatives that are able to establish baselines for various ecosystems and their constituent fauna and flora (Hughes 2003).

We believe that the PPBio approach can support existing SoE reporting mechanisms through the provision of longterm landscape-level monitoring data across a network of permanently marked sites stratified across broad vegetation types (see Magnusson et al 2005). These sites will incorporate a standard suite of 'core' biotic and abiotic data, each resampled regularly at time frames appropriate to each variable, to allow spatial and temporal comparison within and between sites (Magnusson et al 2005; 2008). This would provide baseline information for ongoing information on temporal change, and for additional ecological research at the site. A range of ecological research could be focused in and around such sites, with the aim of providing information for a range of purposes including linkage with remote sensed imagery, vegetation mapping, condition assessment approaches, ecological modelling, etc.

Given adequate cooperation, 'core' data would be freely available to other ecological researchers using the sites with the aims of decreasing duplication and improving information cost-effectiveness. Historically the limited budgets available to conservation science have limited the availability of biodiversity data (Balmford and Whitten 2003) as a result of surveys being targeted to specific indicator or surrogate species. The implementation of a truly integrated multidisciplinary approach that fosters the involvement of a diverse array of scientists is expected to reduce monitoring costs as these are absorbed within individual institutions. However despite the diversity of interests and expertise potentially contributing to data generation from the RAPELD grids these data will be comparable as a result of the standardised nature of the sampling protocols. The principles outlined above support Westoby's (1991) call for greater cooperation and research funding incentives to establish and maintain such sites.

\section{Establishing PPBio - RAPELD long- term ecological research sites within Australasia}

The PPBio Australasia program is coordinated by the Environmental Futures Centre at Griffith University and is focussed on the following:

- Establishing a network of long-term ecological research sites, that form part of the AusLTER and ILTER networks, and are available as a tool for resource managers and scientists globally. These sites contribute to providing the necessary data to inform future environmental management requirements in the face of climate change. There may be a number of more focused research objectives linked to particular sites however the need for such rigorously defined objectives is currently under discussion (Strayer et al 1986, Ferraz et al 2008, Magnusson et al 2008).

- Initiating long-term ecological research sites using RAPELD designs, with permanently marked survey plots (now established at: Karawatha Forest Park in Brisbane, Qld; Lake Broadwater Conservation Park outside Dalby, Qld; and Chitwan National Park (Nepal).

- Coordination of baseline biodiversity assessments at these sites using vegetation surveys as a core component.

- Developing appropriate experimental designs for collaborative projects, and compiling standardised survey methodology for monitoring abiotic and biotic indices of biodiversity.

- Providing internet access and database management support facilitating the storage and dissemination of data from a central location.

- Assisting with the analysis and interpretation of data collected.

\section{Establishing a network of Long-term Ecological Research Sites}

PPBio Australasia follows the RAPELD grid and plot design (described above, and in Magnusson et al 2005; 2008) and has initiated the establishment of these grids at two locations in Queensland and one in Nepal. The first key step is the position of the grid within the landscape of interest. This is undertaken in a consultative manner between scientists and natural resource managers, generally seeking to sample the longitudinal, latitudinal and altitudinal gradients with attention to threatened species or ecosystems. The actual grid position on the site is determined using GIS mapping overlays, with the positioning of the grid maximising the number of plots and avoiding any large infrastructure such as roads and or buildings (Figure 1). Additionally or alternatively, modules (grids smaller than $5 \times 5 \mathrm{~km}$, with smaller numbers of plots) can be used to incorporate additional habitats or land uses if required (e.g. vegetation types, corridors or areas under specific management regimes), or to obtain representative coverage of larger areas. The grid is preferably marked as a system of trails (Magnusson et al 2005), or virtual trails (followed by researchers using a GPS and/or compass).

Standardised RAPELD plots are generally placed at $1 \mathrm{~km}$ intervals, evenly distributed along the $5 \times 5 \mathrm{~km}$ grid (Magnusson et al 2005). Individual plots start midway between trail intersections (Figure 2). The $1 \mathrm{~km}$ spacing is designed to promote independence of data between plot locations although grids with smaller intervals are possible and can be used to test for spatial independence among plots but also finer scale ecological processes. Each $250 \mathrm{~m}$ plot midline is permanently marked with a metal stake every $10 \mathrm{~m}$ (Figure 3a). Trees closest to the start and finish of the midline are marked with 2 thin bands of clear reflective paint (Figure $3 \mathrm{~b}$ ) while trees within $2 \mathrm{~m}$ of the permanent stakes are marked with a single thin band 


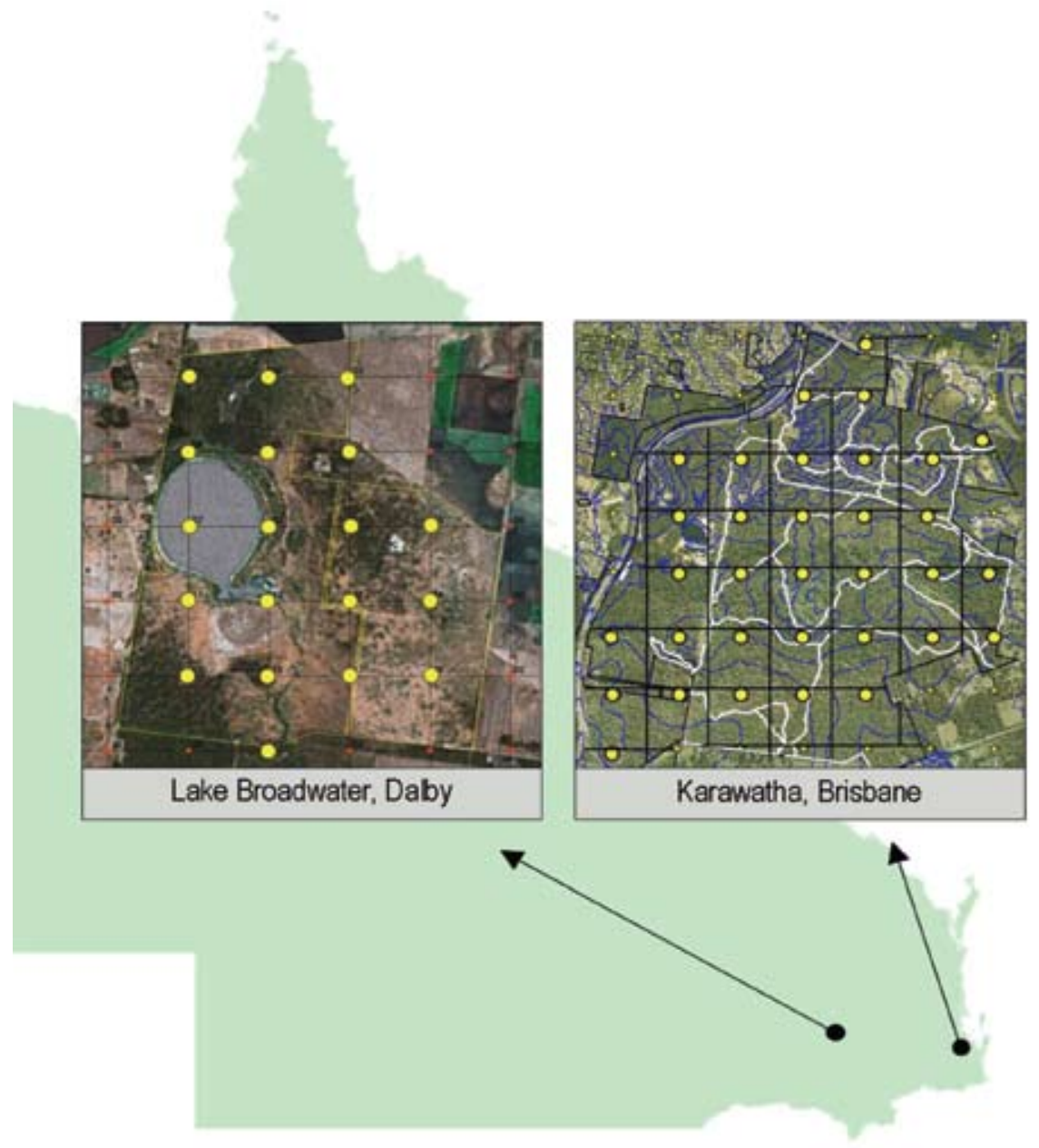

Figure I. Location and layout of PPBio RAPELD grids established in Queensland at Lake Broadwater (Dalby Shire), with 19 plots at $1 \mathrm{~km}$ intervals, and at Karawatha Forest Park (Brisbane City) with 33 plots at 500m intervals. Plots are represented by yellow circles.

(Figure 3c). Clear reflective paint is a subtle indicator of the plot locations that is barely visible during daylight hours but facilitates nocturnal research activities. Plot midlines and stake positions are recorded at $50 \mathrm{~m}$ intervals along the midline using a handheld GPS.

Plot midlines follow topographical contours such that all the permanent markers are at the same altitude. The starting direction for each transect is arbitrarily determined to be in an easterly or westerly direction (depending on the position of the grid in relation to anthropogenic disturbances). Each centre line is a series of straight $10 \mathrm{~m}$ sections (Figure 4) with the position of each stake accurately determined by using a laser level and a $10 \mathrm{~m}$ chain. If the transect bisects a road (or any other anthropogenic disturbance) it is stopped and restarted on the other side of the road with a $10 \mathrm{~m}$ buffer zone on either side of the disturbance. This plot design minimises within plot altitudinal, edaphic, topographic, and plant structure and composition variability (Costa et al 2005) and facilitates orthorectification and validation of satellite imagery, such as digital elevation modelling (SRTM) and forest structure assessment (LIDAR). Aspect is measured by taking a compass bearing looking down the slope, while slope is measured with a clinometer along a $5 \mathrm{~m}$ strip centred on the midline and perpendicular to the elevation contour.

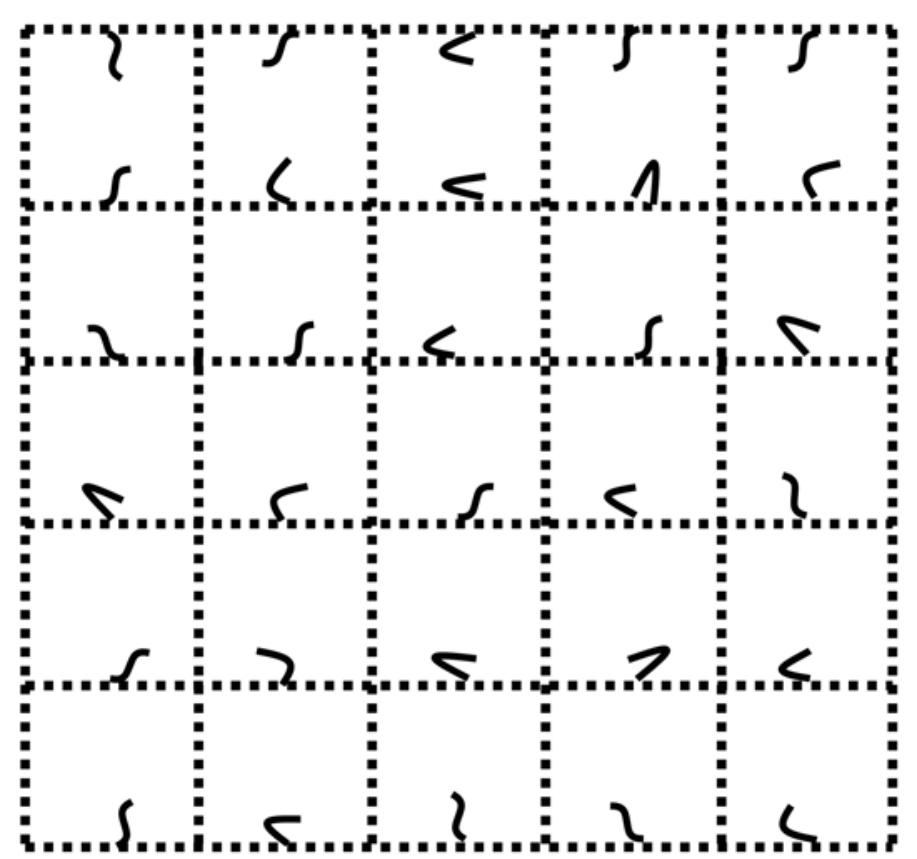

Figure 2. Illustration of the standard PPBio RAPELD grid system with plot midlines shown to follow contours between a $1 \mathrm{~km}$ by $1 \mathrm{~km}$ system of walking trail. 


\section{Data Collection and Biodiversity Monitoring}

This section focuses on the value of the PPBio network of RAPELD grids as long-term ecological research sites for monitoring biodiversity and ecosystem processes; however these sites are also able to facilitate integrated studies from other disciplines including socio-economic analyses. One of the strengths of the approach is that it enables managers to relate biodiversity management issues directly with associated socio-economic constraints. Any number of biodiversity or biophysical variables may be recorded on each plot within a grid, only limited by funding and scientific resources. Standard measures during plot establishment include aspect and slope recorded every $50 \mathrm{~m}$ along the midline ( 6 measures per plot) and summarised as plot averages.

Plot width varies to suit the taxon or abiotic variable being examined. Small and/or numerous taxa are surveyed in narrow plots (e.g. reptiles or herbs and grasses are within a $2 \mathrm{~m}$ strip on one side of the midline) while wide plots are used for larger or more dispersed organisms (e.g. large trees or small mammals). Low density species and additional environmental variables are monitored using the larger series of grid trails (e.g. hollow trees, large mammals) using standard distance sampling methodologies and determination of detection functions for specific taxa (Buckland et al 1993, 2004) which will be a function of vegetation density.

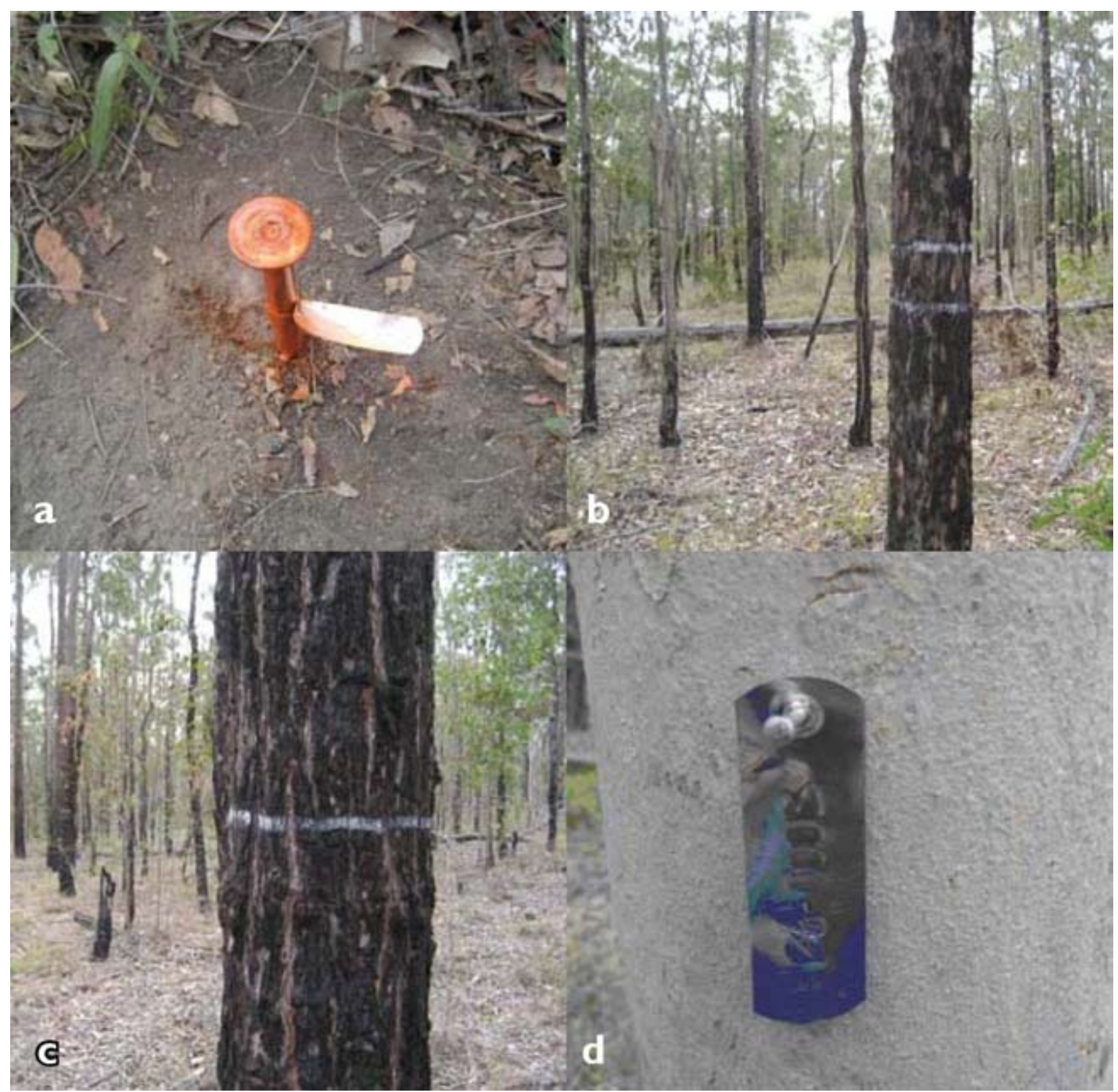

Figure 3. (a) Example of a tagged metal stake used to identify the location of the $10 \mathrm{~m}$ intervals along the plot midline. (b) Marking of trees to identify the start and end of the $250 \mathrm{~m}$ plot midline. The tree nearest to the starting point is marked with a double ring, (c) The tree nearest to each $10 \mathrm{~m}$ peg along the midline. Trees are marked using reflective paint that is discreetly visible during daylight hours and facilitates nocturnal research activities, and (d) Example of an aluminium tag used to mark individual trees over $1 \mathrm{~cm} \mathrm{DBH}$ and placed at $140 \mathrm{~cm}$ above ground level. 


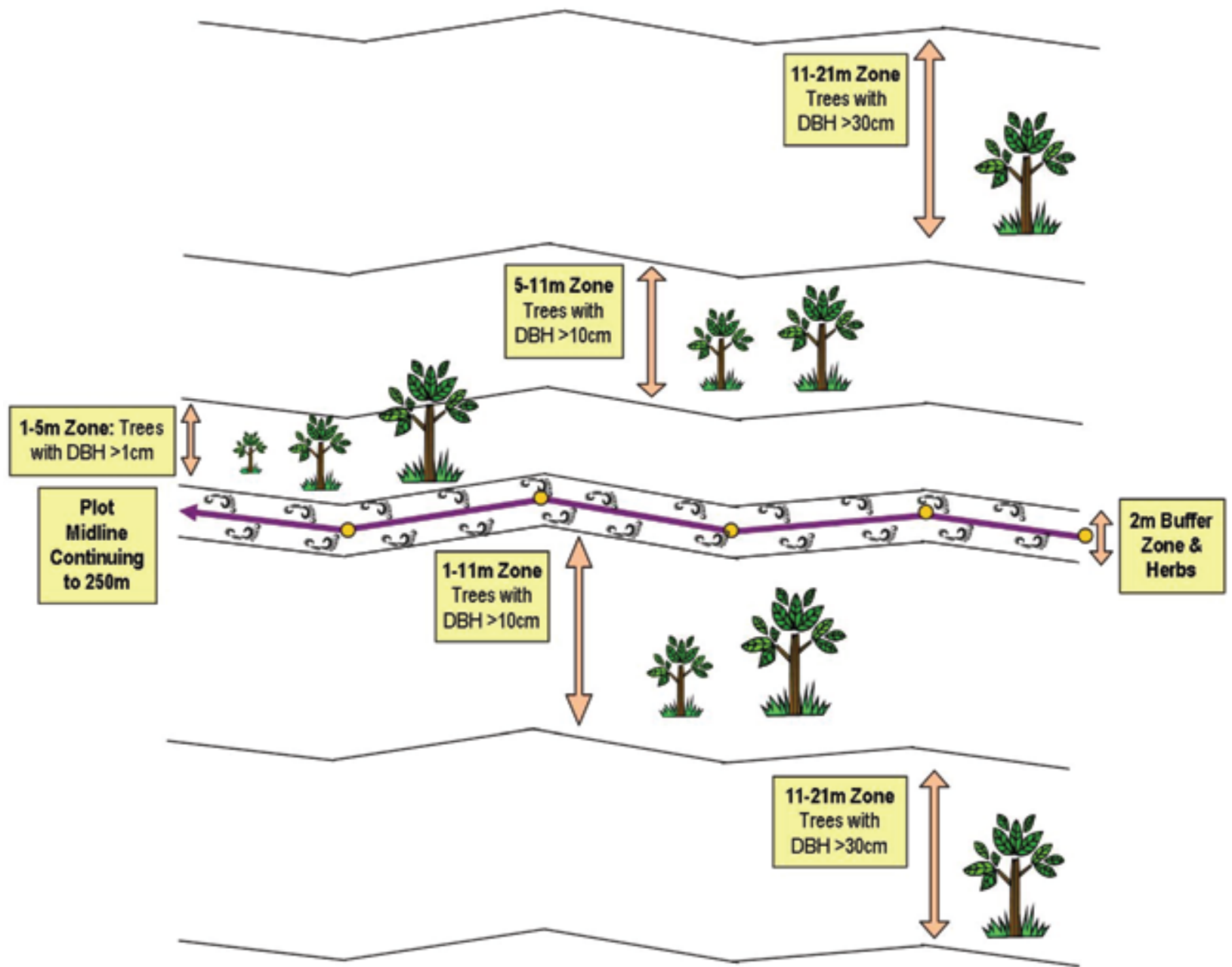

Figure 4. Illustration of the RAPELD plot design. The midline is marked with metal stakes at IOm intervals (represented by yellow circles). Lines represent variable width of the plot in response to the size (DBH for vegetation) and or density of the organism being measured.

One of the core variables for monitoring of the PPBio grids is vegetation condition. As part of the initial setup at Karawatha, we individually tagged (Figure $3 \mathrm{~d})$, identified, measured ( $\mathrm{DBH}$ at $1.3 \mathrm{~m})$, and mapped (distance along the plot midline and perpendicular distance away from the plot midline) all woody stems (trees and shrubs) with $\mathrm{DBH}>1 \mathrm{~cm}$ within plots. A hierarchical design was used to sample trees of different size classes in order to estimate tree density in each plot (Figure 4). Large trees $(\mathrm{DBH} \geq 30 \mathrm{~cm})$ were sampled to $20 \mathrm{~m}$ either side of the midline $(40 \mathrm{~m}$ $x 250 \mathrm{~m} \approx 1$ ha). Trees with $\mathrm{DBH} \geq 10 \mathrm{~cm}$ were sampled within $10 \mathrm{~m}$ either side of the midline $(20 \mathrm{~m} \times 250 \mathrm{~m}$ $\approx 0.5 \mathrm{ha})$. Trees with $\mathrm{DBH} \geq 1 \mathrm{~cm}$ were sampled along a $4 \mathrm{~m}$ strip on the RHS of the midline $(4 \mathrm{~m} \times 250 \mathrm{~m} \approx$ 0.1 ha). Each plot varies slightly in area because of differences in the midline trajectory (which follows the contour line), and the area is calculated in a GIS program using the appropriate buffer width. To minimise trampling disturbance resulting from accessing the plots within the grid, a $2 \mathrm{~m}$ buffer strip is retained along the plot midline ( $1 \mathrm{~m}$ on either side).

\section{Storage and dissemination of data}

All data collected during surveys will be publicly available on a dedicated internet site (http://www.griffith.edu.au/ ppbio) together with the associated metadata, for use by land managers and other scientists alike. Data owners are required to present their metadata at the start of their projects to enable others to replicate protocols at additional sites if necessary, and may take advantage of a two year window to publish results before these data are released to the wider scientific community. This protocol aims to avoid the loss of plot data through poor record keeping and/or the hoarding of data, and thereby maximise the availability of quality long-term data.

\section{Current PPBio activities in the Australasian region}

The PPBio Australasia program began in 2006 and we have now initiated RAPELD grids with permanent plots at Karawatha Forest Park (KFP) in Brisbane, Lake Broadwater Conservation park in Dalby Shire, Queensland, Australia, and internationally at Chitwan 
National Park in Nepal. Herein we briefly describe each of these initiatives to demonstrate the flexibility in the modular strategy used to collect systematic and comparable data within and among sites.

The first Australian PPBio site was established in collaboration with Brisbane City Council, South- east Queensland Catchments and the Nature Refuge Landholders Association in January 2007. The size and location of the reserve within an urban matrix necessitated a reduction in the standard $1 \mathrm{~km}$ spacing of plots to $500 \mathrm{~m}$ intervals resulting in 33 plots (Figure 5). Initial data analysis from the core vegetation surveys suggests there is

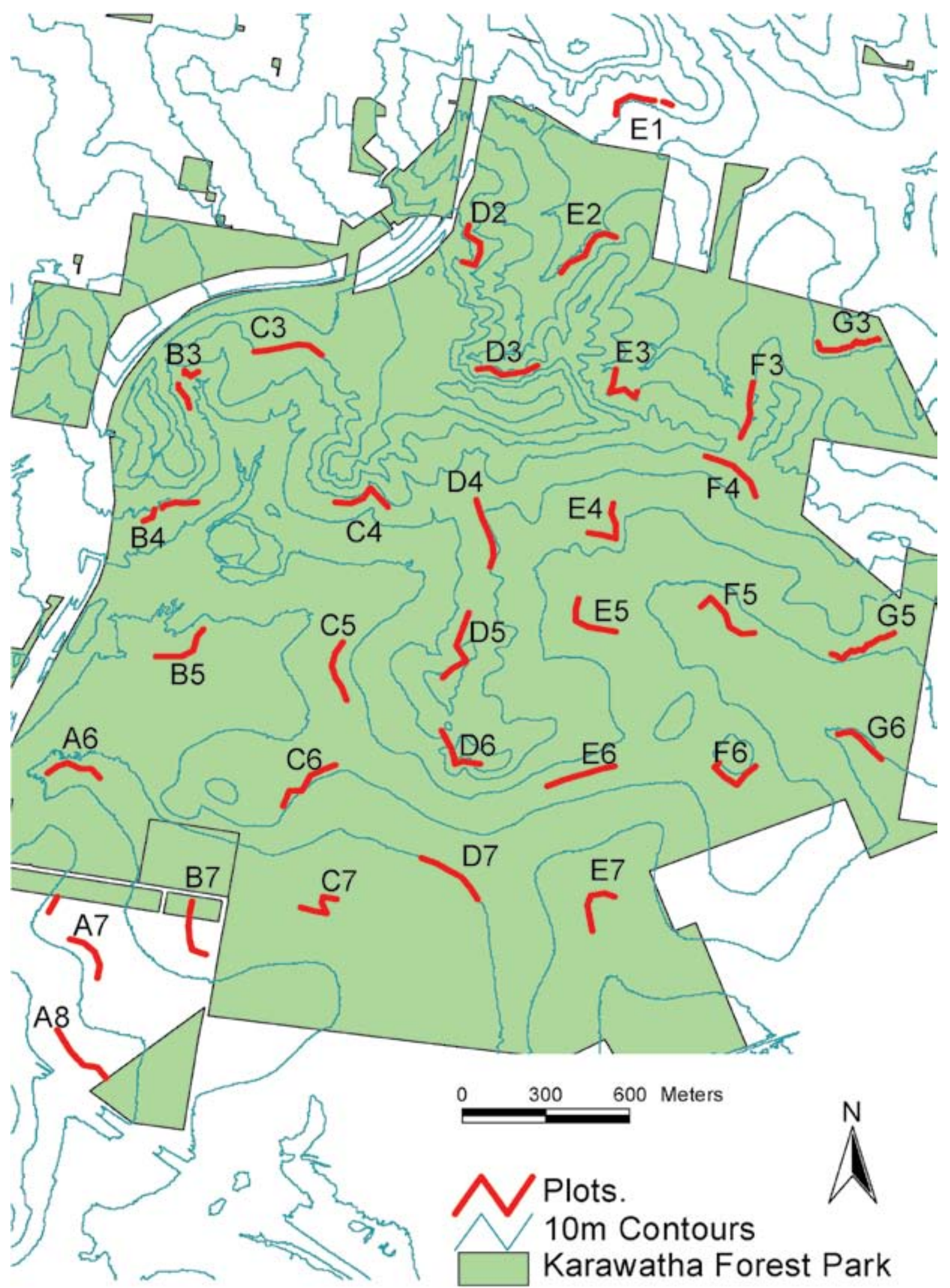

Figure 5. Illustration of PPBio plot midlines following the contours of Karawatha Forest Park, Brisbane, QLD. 
little spatial pseudoreplication even at this finer scale, and presents an ideal opportunity to examine the influence of scale on long-term ecological data sets. The first series of ecological baseline projects were initiated during 2007 and included assessments of soil characteristics, fire history, aspect, slope, vegetation structure and composition, and relative densities of reptiles, amphibians and birds. Although completed as a series of individual projects, the systematic and standardised nature of these surveys will enable us to examine the interactions allowing us to investigate ecosystem processes at the meso-scale (e.g. influence of fire on vegetation and reptile communities). Two $\mathrm{PhD}$ projects are now examining "Sustainable Indicators for Terrestrial Ecosystems" (SITEs including fauna, flora and abiotic indices) and "Predicting and Measuring the Impact of Climate Change on Frogs of South-east Queensland".

In September 2007, a second grid was established at Lake Broadwater, near Dalby in Southern Queensland. Here a $5 \times 6 \mathrm{~km}$ grid was overlaid across the reserve to capture 19 plots at $1 \mathrm{~km}$ intervals (Figure 1) including riparian Red Gum forest, Pilliga forest, Brigalow and grassland habitats. Five plots were established during an undergraduate "Conservation Biology" field trip and an additional 14 plots are planned for subsequent field trips. A core series of vegetation and fauna surveys have also been initiated.

In December 2007 we also initiated a PPBio - RAPELD grid in Chitwan National Park in southern Nepal in collaboration with World Wildlife Fund Nepal, the National Trust for Nature Conservation (NTNC), the Department of National Parks and Wildlife Conservation (DNPWC) and Tribhuvan University. Research is facilitated by local scientists (universities, institutes of higher education and research centres). At Chitwan, a standard RAPELD $5 \mathrm{x}$ $5 \mathrm{~km}$ grid has been identified, and includes 30 plots at $1 \mathrm{~km}$ spacing within riparian forest and grassland along the Rapti River floodplain, and in the Sal forest of the adjacent Churia Hills (Figure 6). The first 5 plots were established during a pilot study in December 2007.

The variation in the application of the PPBio grid and plot system demonstrates how the modular system can be flexible to suit the scale of the project and the physical constraints of the landscape. Despite changes in scale (reduced to $500 \mathrm{~m}$ intervals at Karawatha) and the number of plots reduced to 19 at Lake Broadwater, the core elements of the program (e.g. $250 \mathrm{~m}$ plots following the isoclines, replication of plots, etc) remain unchanged. This enables us to use the same sampling techniques (metadata and sampling protocols available on the internet site) and collect comparable relational data sets from all sites.

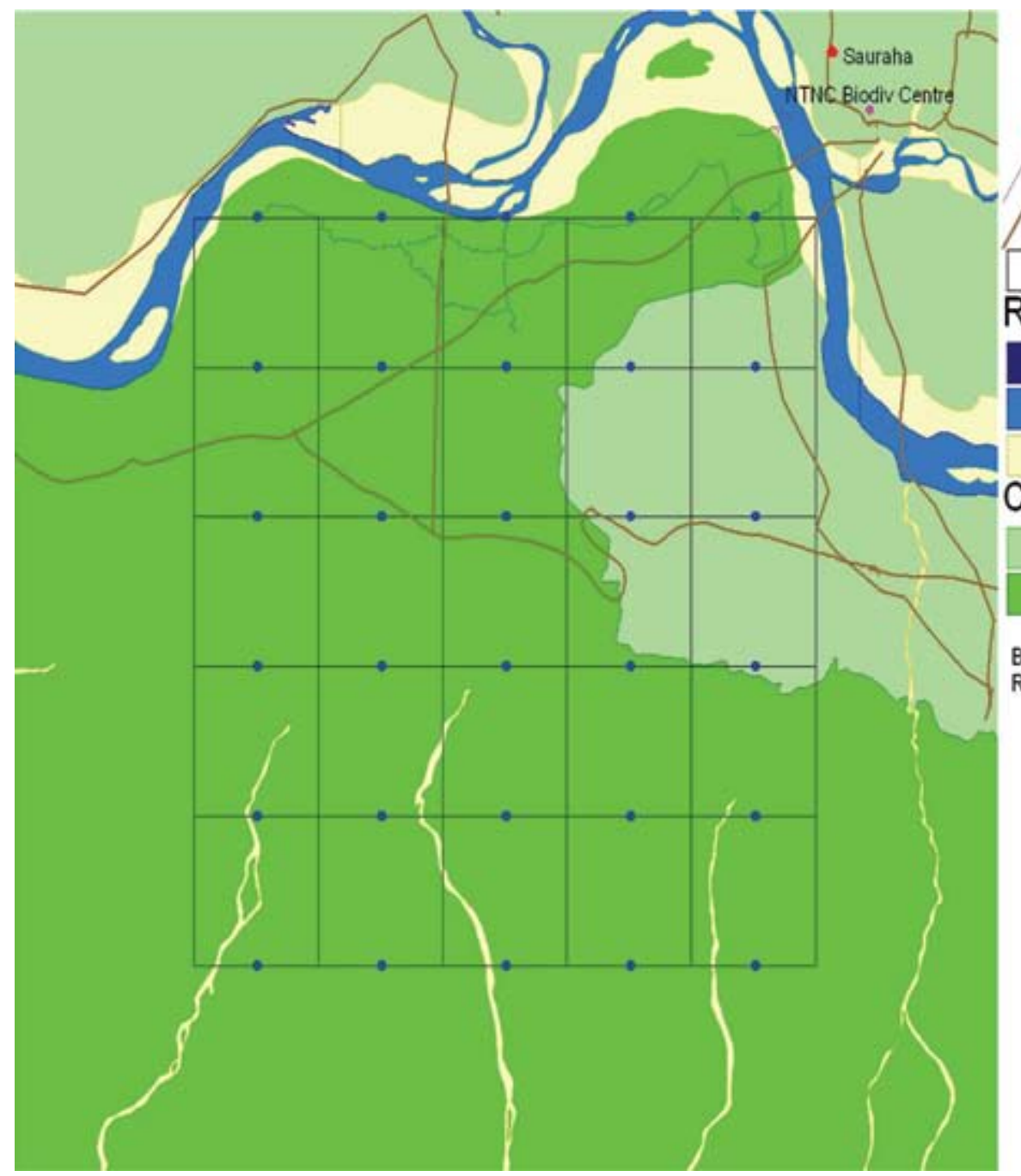

- PPBio Plots - Locations - Settlements Trails Roads PPBio Grid River / Drainage Lake/Pond River Sand/gravel Chitwan Boundaries RCNP BZ RCNP Core

Figure 6. Location of PPBio RAPELD plots in Chitwan National Park, Nepal, with 30 plots at I km intervals. 


\section{The PPBio Australasia vision}

The aim of PPBio Australasia (as part of the international PPBio program) is to establish PPBio - RAPELD grids and/or modules in all of the major biogeographic regions throughout eastern Australia. We are currently preparing three proposals to establish a network of RAPELD grids following longitudinal, latitudinal and altitudinal gradients in eastern Australia (Figure 7).

1. The first proposal includes a minimum of 8 RAPELD grids linked to the Great Eastern Ranges Initiative (formerly A2A Connectivity Conservation Project, Worboys 2007b) spanning from the Alps to Atherton to include climate refuge areas. These sites would include modules crossing the Great Dividing Range, with permanently marked plots at every $200 \mathrm{~m}$ of elevation to detect potential biome shifts in response to climate change.

2. The second proposal includes a combination of PPBio - RAPELD grids and modules following an east - west longitudinal / rainfall gradient from Brisbane (existing Karawatha grid) extending westward into the arid region of central Australia to detect potential biome shifts in response to climate change.

3. The third proposal includes a minimum of 20 PPBio - RAPELD modules in coastal heath sites between Jervis Bay in NSW and Fraser Island in Queensland to monitor coastal systems in response to climate change. Within each site a minimum of 4 plots will be placed within waterbodies (coastal wetlands) with adjacent terrestrial plots to monitor terrestrial vegetation.

Implementing a network of PPBio - RAPELD grids throughout Australasia will allow us to measure Sustainable Indicators for Terrestrial Ecosystems (collected by local research organisations with an emphasis on involving postgraduate students from local tertiary institutions) that can provide long-term, comparable data that will be suitable for incorporating into State of the Environment Reporting at all levels of government (local, state and federal).

\section{Proposed PPBio LTER grids}

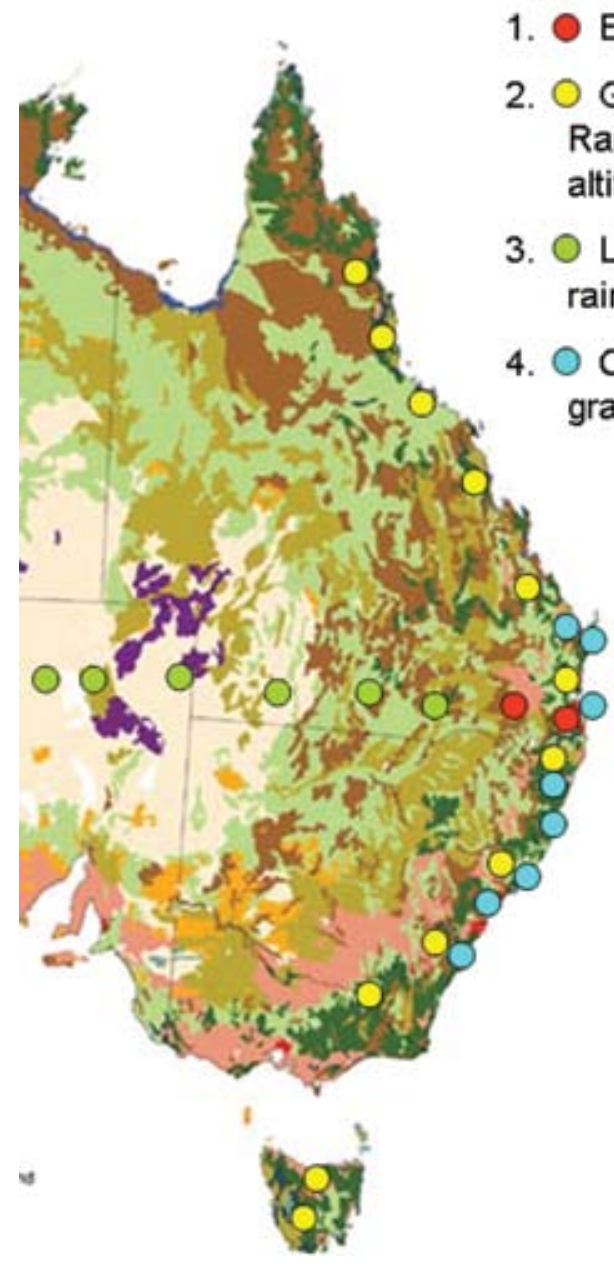

Figure 7. Graphic representation of the vision for PPBio Australasia: to establish RAPELD LTER grids in major biogeographic regions throughout Australia.

\section{Acknowledgements}

The success of the PPBio project lies in its broader support base and research network. PPBio Karawatha could not have been initiated without financial support from Brisbane City Council (BCC), South East Queensland Catchments Inc. and Griffith University. Logistic support was also provided by the Nature Reserve Landholders Association (NaRLA) and the Australian Conservation Volunteers and staff from BCC Biodiversity Planning and BCC Natural Area managers. Furthermore, the dedication and hard work of Griffith University staff and students, and the many volunteers, have been pivotal to the projects success, and will continue to be so into the future. Special thanks to Gordon Grigg and Lyn Beard for organising and inviting us to participate in the Ecology meets Physiology Conference.

\section{References}

Australian and New Zealand Environment and Conservation Council, State of the Environment Reporting Task Force 2000. Core environmental indicators for reporting on the state of the environment. Environment Australia, Canberra.

Beeton R.J.S., Buckley K.I., Jones G.J., Morgan D., Reichelt R.E. and Trewin D. 2006. Australia State of the Environment 2006, Independent report to the Australian Government Minister for the Environment and Heritage, Department of the Environment and Heritage, Canberra.
Balmford, A. and Whitten, T. 2003. Who should pay for tropical conservation, and how could the costs be met? Oryx 37: 238-250.

Bosch, O.J.H., Ross, A.H. and Beeton, R.J.S. 2003. Integrating science and management through collaborative learning and better information management. Systems Research and Behavioural Science 20: 107-118.

Brazilian Ministry of Science and Technology. 2006. Program for Planned Biodiversity Studies (http://ppbio.inpa.gov.br) (accessed 14th March 2006). Brazilian Ministry of Science and Technology. 
Buckland, S.T., Anderson, D.R., Burnham, K.P. and Laake, J.L. 1993. Distance Sampling: Estimating Abundance of Biological Populations. Chapman and Hall, London. Pp 446.

Buckland, S.T., Anderson, D.R., Burnham, K.P., Laake, J.L., Borchers, D.L. and Thomas, L. 2004. Advanced Distance Sampling: Estimating Abundance of Biological Populations. Oxford University Press. London, Pp 434.

Burbidge A. A. 1991. Cost constraints on surveys for nature conservation. Pp. 3-6 in Nature conservation: cost effective biological surveys and data analysis edited by C. R. Margules and M. P. Austin. CSIRO, Canberra.

Callahan, J.T. 1984. Long-term ecological research. Bioscience 34: 363-367.

Chapman A. D. and Busby J. R. 1994. Linking plant species information to continental biodiversity inventory, climate modeling and environmental monitoring. Pp. 179. 94 in Mapping the diversity of nature edited by R. I. Miller. Chapman \& Hall, London.

Condit, R. 1995. Research in large, long-term tropical forest plots. Trends in Ecology and Evolution 10: 18-22.

Condit, R. 1998. Tropical forest census plots: methods and results from Barro Colorado Island, Panama and a comparison with other plots, Berlin, Springer-Verlag.

Costa F.R., Magnusson W.E and Luizao R. C. 2005. Mesoscale distribution patterns of Amazonian understorey herbs in relation to topography, soil and watersheds. Journal of Ecology 93: 863-878.

Craine, J.M., Battersby, J., Elmore, A.J., Jones, A.W. 2007. Building EDENs : The rise of Environmentally Distributed Ecological Networks. Bioscience 57: 45-54.

DEFRA 2003. A biodiversity strategy for England: measuring progress, a baseline assessment. England Biodiversity Group, Department for Environment, Food and Rural Affairs. London. Online 25/09/08 - http://www.defra.gov.uk/wildlife-countryside/ biodiversity/biostrat/indicators/pdf/indicators031201.pdf

DEH. (2005) Ecological communities and the EPBC Act (www.deh.gov.au/epbc/policy/index.html). Department of the Environment and Heritage, Australian Government, Canberra.

EPA. 1999. Forest monitoring plot network in South Queensland. Environmental Protection Agency, Brisbane.

Eyre, T.J., Kelly, A.L. and Neldner, V.J. 2006. BioCondition: A terrestrial vegetation condition assessment tool for biodiversity in Queensland. Field Assessment Manual. Version 1.5.Environmental Protection Agency, Biodiversity Sciences unit. Brisbane.

Ferrari, I. and Ferrarini, A. 2008. From ecosystem ecology to landscape ecology: a progression calling for a well founded research and appropriate disillusions. Landscape Online 6:1-12.

Ferraz, G., Marinelli, C. E. and Lovejoy, T. E. 2008. Biological monitoring in the Amazon: Recent progress and future needs. Biotropica 40:7-10.

Ferrier S. 1997. Biodiversity data for reserve selection: making best use of incomplete information. Pp. 315-29 in National parks and protected areas: selection, delimitation and management edited by J. J. Pigram and R. C. Sundell. Centre for Water Policy Research, University of New England, Armidale.

Gardner, T.A., Barlow, J., Araujo, I.S., Avila-Pires, T.C., Bonaldo, A.B., Costa, J.E., Esposito, M.C., Ferreria, L.V., Hawes, J., Hernandez, M.I.M., Hoogmoed, M.S., Leite, R.N., Lo-Man-Hung, N.F., Malcolm, J.R., Martins, M.B., Mestre, L.A.M., Miranda-Santos, R., Overal, W.L., Parry, L., Peters, S.L., Ribeiro-Junior, M.A., da Silva, M.N.F., da Silva Motta, C. and Peres, C.A. 2008. The cost-effectiveness of biodiversity surveys in tropical forests. Ecology Letters 11: 139-150.
Gibbons P., Ayers D., Seddon J., Doyle S. and Briggs S. 2005. BioMetric Version 1.8 A Terrestrial Biodiversity Assessment Tool for the NSW Property Vegetation Plan Developer Operational Manual Department of Environment and Conservation (NSW), Canberra. Available from URL: http://www.nationalparks.nsw. gov.au/npws.nsf/content/biometric_tool.

Gioia P. 2005. Improving information management within CALM: the results of a study tour in March, 2005 of five other conservation agencies within mainland Australia (Draft Report). Pp. 53, Department of Conservation and Land Management, Perth.

Hahs, A. 2001. Long term ecological research in Australia. Bulletin of the Ecological Society of Australia 31: 11-14.

Hintermann, U., Weber, D., Zangger, A. and Schmill, J. 2002. Biodiversity Monitoring in Switzerland, BDM Interim Report. Swiss Agency for the Environment, Forests and Landscapes. SAEFL Series No. 342. Pp 89.

Hobbie, J.E., Carpenter, S.R., Grimm, N.B., Gosz, J.R. and Seastedt, T.R. 2003. The US long term ecological research program. Bioscience 53: 21-32.

Hughes, L. 2000. Biological consequences of global warming: Is the signal already apparent? Trends in Ecology and Evolution 15: 56-61.

Hughes, L. 2003. Climate change and Australia: Trends, projections and impacts. Austral Ecology 28: 423-443.

Keith D. and Bedward M. 1998. Forest ecosystem classification and mapping for the Eden Comprehensive Regional Assessment. Pp. 20, Joint Commonwealth NSW Regional Forest Agreement Steering Committee, Sydney.

Kelly A., Haseler M., Ferguson D., Wang J., Mathieson M., Venz M. \& Lawrence A. 2003. Assessment of forest values within the western Queensland hardwood region. Pp. 78. Environmental Protection Agency, Brisbane.

Lane, A.M.J. 1997. The U.K. Environmental Change Network Database: An integrated information resource for long-term monitoring and research. Journal of Environmental Management 51: 87-105.

Lawson B. E., Ferrier S., Wardell-Johnson G., Pullar D. V. and Beeton R. J. S. 2007 The use of species compositional dissimilarity to assess the effectiveness of ecological classification schemes. Pp. 558-9 in 25 years of landscape ecology: scientific principles in practice. Proceedings of the 7th International Association for Landscape Ecology 2007 Conference, edited by R. G. H. Bunce, R. H. G. Jongman, H. L. and S. Weel. IALE Publication Series 4, Wageningen, The Netherlands.

Lindenmayer, D.B., Margules, C.R. and Botkin, D.B. 2001. Indicators of biodiversity for ecologically sustainable forest management. Conservation Biology 14: 941-950.

Lunt, I.D. 2002. Grazed, burnt and cleared: how ecologists have studied century-scale vegetation changes in Australia. Australian Journal of Botany 50: 391-407.

Magnusson W.E., Lima A.P., Luizao R., Luizao F., Costa F.R.C., de Castilho C.V. and Kinupp V.F. 2005. RAPELD: a modification of the Gentry method for biodiversity surveys in long-term ecological research sites. Biota Neotropica 5: 1-6.

Magnusson, W.E., Costa, F., Lima, A., Baccaro, F., BragaNeto, R., Laerte Romero, R., Menin, M. , Penha, J., Hero, J.-M. and Lawson, B.E. 2008. A Program for Monitoring Biological Diversity in the Amazon: An Alternative Perspective to Threat-based Monitoring. Biotropica 40: 409-411. 
McCarthy M.A., Parris K.M. van der Ree R., McDonnell M.J., Burgman M.A., Williams N.S.G., McLean N., Harper M.J., Meyer R., Hahs A. and Coates, T. 2004. The habitat hectares approach to vegetation assessment: An evaluation and suggestions for improvement. Ecological Management $\mathfrak{B}$ Restoration 5: 24-27.

Mendonca, F.P., Magnusson, W.E. and Zuanon, J. 2005. Relationships between habitat characteristics and fish assemblages in small streams of central Amazonia. Copeia 4:750-763.

Neldner V.J., Wilson B.A., Thompson E.J. and Dillewaard H.A. 2004. Methodology for survey and mapping of vegetation communities and regional ecosystems in Queensland (Version 3.0). Queensland Herbarium, Environmental Protection Agency, Brisbane. Pp. 107.

Nielsen, S.E., Bayne, E.M., Schieck, J. Herbers, J. and Boutin, S. 2007. A new method to estimate species and biodiveristy intactness using empirically derived reference conditions. Biological Conservation 137: 403-414.

NLWRA. 2002. Australian Terrestrial Biodiversity Assessment 2002. National Land and Water Resources Audit, Canberra.

NLWRA. 2004a. Assessment of data requirements and availability to address natural resource condition and trend indicators. National Land \& Water Resources Audit and Beaten Track Group Pty Ltd, Canberra. Pp. 130.

NLWRA. 2004b. Monitoring and Evaluation: Queensland Regional Trials, Phase 1 Report,. National Land \& Water Resources Audit, Canberra.

Parkes D., Newell G. and Cheal D. 2003. Assessing the quality of native vegetation: the 'habitat hectares' approach. Ecological Management and Restoration 4: 29-38.

Parr, T.W., Sier, A.R.J., Battarbee, R.W., Mackay, A. and Burgess, J. 2003. Detecting environmental change: science and society - perspectives on long-term research and monitoring in the $21^{\text {st }}$ century. The Science of the Total Environment 310: 108.

Pereira H.M. and Cooper H.D. 2006. Towards the global monitoring of biodiversity change. Trends in Ecology and Evolution 21: 123-9.

Purvis, A. and Hector, A. 2000. Getting the measure of biodiversity. Nature 405: 212-219.

Productivity Commission 2004. Impacts of native vegetation and biodiversity regulations. Productivity Commission, Melbourne. Pp. 588
Saunders D., Margules, C. and Hill, B. 1998. Environmental Indicators for National State of the Environment Reporting: Biodiversity, Australia: State of the Environment (Environmental Indicator Reports), Department of the Environment, Canberra

Sinclair R. 2005. Long-term changes in vegetation, gradual and episodic, on the TGB Osborn Vegetation Reserve, Koonamore, South Australia (1926-2002). Australian Journal of Botany 53: 283-96.

Stork, N.E., Samways, M.J., and Eeley, H.A.C. 1996. Inventorying and monitoring biodiversity. Trends in Ecology and Evolution 11: 39-40.

Strayer, D., Glitzenstein, J.S., Jones, C.G., Kolasoi, J., Likens, G.E., McDonnell, M.J., Parker, G.G. and Pickett, S.T.A. 1986. Long-term ecological studies: an illustrated account of their design, operation, and importance to ecology. Occasional Publication of the Institute of Ecosystem Studies, No.2. Millbrook, New York.

Thackway, R., Lee, A., Donohue, R., Keenan, R.J. and Wood, M. 2007. Vegetation information for improved natural resource management in Australia. Landscape and Urban Planning 79: $127-136$

Westoby M. 1991. On long-term ecological research in Australia. Pp. 191-209 in Long-term ecological research edited by P. G. Risser. John Wiley \& Sons.

Wiser, S.K., Bellingham, P.J. and Burrows, L.E. 2001. Managing biodiversity information: development of New Zealand's National Vegetation Survey databank. New Zealand Journal of Ecology 25: 1-17.

Worboys, G.L. 2007a. Evaluation subjects and methods required for managing protected areas. Ph.D. thesis, Griffith School of Environment, Griffith University, Gold Coast, Australia.

Worboys, G.L. 2007b. Managing Australia's protected areas for a climate shifted spectrum of threats. A paper presented to the IUCN WCPA and WWF-Australia symposium on: Protected areas: Buffering Nature against Climate Change, Academy of Science, Canberra 18-19 June 2007.

Yoccoz, N.G., Nichols, J.D. and Boulinier, T. 2001. Monitoring of biological diversity in space and time. Trends in Ecology and Evolution. 16: 446-453. 


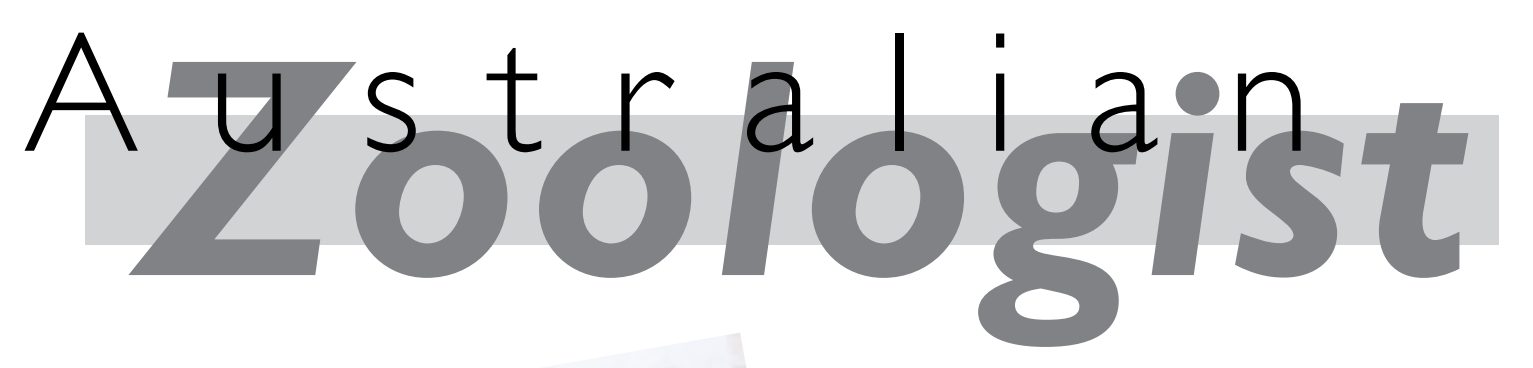

\section{Ecology meets Physiology- A Gordon Grigg festschrift}

Edited by Lyn Beard, Daniel Lunney, Hamish McCallum and Craig Franklin

Royal Zoological Society of New South Wales 